\title{
A NEURO-FUZZY SYSTEM TO SUPPORT IN THE DIAGNOSTIC OF EPILEPTIC EVENTS AND NON-EPILEPTIC EVENTS USING DIFFERENT FUZZY ARITHMETICAL OPERATIONS
}

\author{
Lucimar M.F. de Carvalho', Silvia Modesto Nassar², Fernando Mendes de Azevedo², \\ Hugo José Teixeira de Carvalho ${ }^{3}$, Lucas Lese Monteiro ${ }^{4}$, Ciciliana M. Zilio Rech ${ }^{4}$
}

\begin{abstract}
Objective: To investigate different fuzzy arithmetical operations to support in the diagnostic of epileptic events and non epileptic events. Method: A neuro-fuzzy system was developed using the NEFCLASS (NEuro Fuzzy CLASSIfication) architecture and an artificial neural network with backpropagation learning algorithm (ANNB). Results: The study was composed by 244 patients with a bigger frequency of the feminine sex. The number of right decisions at the test phase, obtained by the NEFCLASS and ANNB was $83.60 \%$ and $90.16 \%$, respectively. The best sensibility result was attained by NEFCLASS ( $84.90 \%)$; the best specificity result were attained by ANNB with $95.65 \%$. Conclusion: The proposed neuro-fuzzy system combined the artificial neural network capabilities in the pattern classifications together with the fuzzy logic qualitative approach, leading to a bigger rate of system success.
\end{abstract}

KEY WORDS: epileptic events, non epileptic events, artificial neural network, fuzzy logic.

\begin{abstract}
Um sistema neuro-difuso para auxiliar no diagnóstico de eventos epilépticos e eventos não epilépticos utilizando diferentes operações aritméticas difusas

Resumo - Objetivo: Investigar diferentes operações aritméticas difusas para auxíliar no diagnóstico de eventos epilépticos e eventos não-epilépticos. Método: Um sistema neuro-difuso foi desenvolvido utilizando a arquitetura NEFCLASS (NEuro Fuzzy CLASSIfication) e uma rede neural artificial com o algoritmo de aprendizagem backpropagation (RNAB). Resultados: A amostra estudada foi de 244 pacientes com maior freqüência no sexo feminino. O número de decisões corretas na fase de teste, obtidas através do NEFCLASS e RNAB foi de $83,60 \%$ e $90,16 \%$, respectivamente. O melhor resultado de sensibilidade foi obtido com o NEFCLASS (84,90\%); o melhor resultado de especificidade foi obtido com a RNAB (95,65\%). Conclusão: O sistema neuro-difuso proposto combinou a capacidade das redes neurais artificiais na classificação de padrões juntamente com a abordagem qualitativa da logica difusa, levando a maior taxa de acertos do sistema.
\end{abstract}

PALAVRAS-CHAVE: eventos epilépticos, eventos não epilépticos, rede neural artificial, lógica difusa.

Although the development of a methodology for a project of neural-fuzzy systems (NFS) is an activity which has been sought for two decades, it has not obtained yet a systematic procedure which may be applied to problems of different fields. This has caused the rise of several proposals which are used in special situations. The proposed article fits in this profile, with the particular feature of not seeking a general architecture, like the other proposals, but of doing an analysis about some decisions of a prior level to the architecture itself to be utilized through fuzzy logic theory and artificial neural network

Fuzzy logic is the science of thinking and reasoning it, is an extension of binary theory that does not use crisp definitions, the fuzzy logic is a method that uses the concept of fuzziness. The properties of the artificial neural network (ANN) in tunning rule based fuzzy system that ap-

'Doctor in Electrical Engineering at Passo Fundo University, Passo Fundo RS, Brazil (UPF); ${ }^{2}$ Doctor in Electrical Engineering at Federal University of Santa Catarina, Santa Catarina, Brazil (UFSC); ${ }^{3}$ Medical Expert at Passo Fundo Hospitals, Passo Fundo RS, Brazil (HC/HSVP); ${ }^{4}$ Student of Computer Science and Medine, UPF.

Received 30 July 2007, received in final form 17 December 2007. Accepted 15 February 2008.

Dra. Lucimar M.F. de Carvalho - Rua Uruguai 379 / 702 - 99010-110 Passo Fundo RS - Brasil. 
proximate the way human reasoning. The synergy of ANN and fuzzy logic takes the advantages from both methodologies for learning, known as NFS.

The main contribution of the work consists of a performance analysis of different fuzzy arithmetic operations. To evaluate the proposal effectiveness, an NFS is proposed to support in the diagnostic involving the epileptic events (EE) and the non epileptic events (NEEs). Through the application and analysis of these operations, it can attain a bigger or smaller system hit rate.

\section{METHOD}

The implemented models use Mamdani's inference method which is based on the Perceptron Multilayer (MLP) model through the reprogramming modified algorithm'.

In order to analyze the different arithmetic operations, the NFS have been developed. The first model has been implemented with the NEFCLASS with $\mathrm{max} / \mathrm{min}$ fuzzy pattern arithmetic operations to solve problems of pattern classifications. It can be used to determine the class or correct category from an entry pattern, which correspond to group symptoms presented by the patients ${ }^{2}$.

The second model, implemented by DELPHI 7.0 language, uses an artificial neural network with backpropagation learning algorithm (ANNB) based on the MLP modified algorithm, through the choice of AND/OR operators in the intermediate layer and the AND/OR in the output layer.

The network learning process consists of updating the synaptic weights, using the Einstein's Product fuzzy arithmetical operation for AND neurons and the Einstein's Sum fuzzy arithmetical operation for OR neurons, implemented with the fuzzy neuron proposed by Kwan-Cai ${ }^{3,4}$.

In the NFS implementation a ANNB with fourteen input units, representing the symptoms showed by the patients and two output units is used, corresponding to an EE or NEE. The NFS input contains quantitative values, which means, quantity of presented symptoms by the patient during an EE or NEE.

In this research, the case base is subdivided into a training base and a test base, both containing parameters come from patients with EEs and NEEs. The case base is composed of two hundred and forty-four patients. Out of this total, 105 showed EEs and 139 showed NEEs. From the 244 cases which have been analyzed, 122 have been chosen at random for the composition of the training base, i.e., 52 patients with EEs and 70 patients with NEEs. The remaining cases were used in implementing the test base in the total amount of 53 patients with EEs and 69 patients with NEEs. The sample period was from March 2002 to May 2006.

The biggest frequency of patients is in the female sex belonging to a lower social class. The kind of sample was not choosen at random, selection of convenience. At the samples colection, it was used the interview technique (directed and non directed) and observation with a medical expert.

The NFS training process is interrupted when the system reaches the smallest square mean error (SME) approximating the NFS exit with a desirable one, which means, the exit given by the medical expert (golden standard). The fixed error criterion was chosen because it has been opted not to use a validation set due to the small number of examples which integrate the case base.

In case of the NFS given exit be different from the one given by the medical expert, the NFS receive new values of synaptic weights and the web is trained to try again. In both models, the NFS was trained with 1,000 epochs. The goal is focused on finding the sufficient number of fuzzy rules which may correctly classify a set of input patterns, involving the EE and NEEs. The group of rules was elaborated together with the medical expert that tries to represent the biggest number of symptoms showed by the patients. When the NFS does not find the rule that satisfies the entrance characteristics (symptoms showed by patients) the NFS automatically generates the correspondent rule.

The variables of the entrance at the NFS, correspondents to epileptics patients data used in the training and test network are registered according to the epilepsy neurological tracking (ENT) ${ }^{5}$. The variables of the entrance in non epileptic patients were implemented altogether with the medical expert. It was by means of ENT that one has determined the variables which integrate the data collection system. After the interview phase, the patients' data were analyzed and, patients with non-existent data were excluded from training and test phase of NFS to support in the diagnostic of epileptic events and non epileptic events.

The model of development of the NFS to support in the clinical diagnosis of the epileptic crises was based on the classification criteria of International League against Epilepsy (ILAE/81) ${ }^{6}$.

According to Nassar ${ }^{7}$, the evaluation of the expert systems occurs by means of two phases: (1) evaluation of the performance system and (2) internal evaluation of the knowledge base. In this research, the implemented statistic analyses include the performance evaluation of the learning models and the internal evaluation of the knowledge base, both of them being applied in the NFS test phase.

In evaluating the performance of the models, one has chosen the hypothesis test which is grounded on an experimental situation. The hypothesis test for proportions has been chosen in view of the goal to compare the t-norms and t-conorms fuzzy arithmetical operations with the fuzzy pattern arithmetical operations which were implemented with the NEFCLASS architecture, in order to either accept it or reject it ${ }^{8}$.

The research project has been approved by the Ethics Committee of research of the Passo Fundo University.

\section{Epilepsy}

The World Health Organization (WHO) defined epilepsy as a disturbance of the brain, of varied etiologies, characterized by the consequent recurring crises to the excessive discharge of the cerebral neurons, including the epilepsy in the mental upset chapter. People with epilepsy suffer from stigma and when left without treatment, suffer from serious dysfunctions. The treatment for epilepsy is frequently under the responsibility of mental health professionals, due to the great prevalence and the rel- 
ative absence of specialized neurological services, especially in countries under development ${ }^{9}$.

The epilepsy is the most common neurological disease in population in general. One of the main worries of the psychiatrists involving this pathology is the consideration of an epilepsy diagnosis in psychiatrists patients ${ }^{10}$. Due to this reason, nowadays, researches have been developed including neurology and psychiatric aspects of epilepsy looking for an integration theory-practice between the two medical experts"

Due to the uniformity lack in the classification of the epilepsies the ILAE established an international committee to try to standardize it. They looked for the criteria in the information that can be obtained from the patients (history and clinical exam) and in the characteristics of the electroencephalogram. The first step to the diagnosis is to define if the episodes are truly epileptic or non epileptic. The history must include the description of the initial symptoms, the critical manifestations and the after critical symptoms ${ }^{12}$. At this way, it is necessary the investigation of different qualifying systems that serve as a supportive architecture to the diagnosis involving EEs and NEEs.

After an analysis of the main features involving epilepsies and performed along with the medical expert, one has been chosen, among the variables which involve the definition of EEs and NEEs, fourteen determining features which integrate EEs and NEEs ${ }^{5,6,12-14}$.

The features which attack NEEs are: (1) conversion classical symptoms, including pharyngeal spasms, digestive disturbances, contractions, body ache and paralysis; (2) sensibility disturbances (anesthesia) and sensory activity disturbances; (3) emotional factors (4) behavioral, convertible, dissociatable disturbances including panic, flights, depersonalization, somatization, hypochondria and simulation; (5) swoons and (6) disturbances, including sleep, arrhythmical endocrinal movements and fever crisis.

The features that involve the EEs are: (7) partial signs and symptoms; (8) during fainting they saw something; (9) during fainting they heard something; (10) during fainting they bit their tongue; (11) during fainting they hurt themselves; (12) duration of crises (13) after critical events, including mental confusion, sleepiness, paralyses, vomiting and body ache; (14) generalized tonic, clonic, tonic-clonic, absence seizure (petit mal), atonic signs and symptoms. The symptoms described, including EEs and NEEs, integrate the NFS entrance variants (fuzzy neuron), registered according to the epilepsy neurological tracking (ENT) ${ }^{5}$ and was based on the classification criteria of International League against Epilepsy (ILAE/81) .

The research is based on the main hybrid learning algorithms found in literature ${ }^{15-23}$, among others.

\section{Learning models}

Initially, the NEFCLASS architecture implements a rule base generated to meet, for each pattern in the training set; a rule which best classifies it. If a rule with an identical antecedent does not exist in the rule base, then this rule will be created. After all the patterns have been processed, the rule base will be complete ${ }^{24}$.
The NEFCLASS present fourteen entry units, one hundred forty-nine fuzzy rules and three exit units. The system has feed forward network architecture with three layers called C1, C2 e $C_{3}$. The layer $C_{1}$ represents the numeric entry of $\left(x_{1}, x_{2} \ldots x_{14}\right)$ values, describing the features of the input patterns to be classified symptoms presented by the patients

The Layer $C_{1}$ selects the input patterns. Each $x_{i}$ input patterns meets its $(\mu)$ pertinence function according to its respective fuzzy set. In layer $C_{2}$ the fuzzy rules for classification are implemented by using E operator through the t-norms ( $\mathrm{min}$ ) function. This layer contains one mode for each IF-THEN fuzzy rule.

The fuzzy rules for classification are implemented in the following way:

\section{IF $\left(x_{1}\right.$ igual $\left.A_{i r}\right) E \ldots . . . E\left(x_{n}\right.$ igual $\left.A_{n r}\right)$ THEN class $C_{j r}$} where,

$x_{n}$ represents the features of the input patterns;

$r$ represents the rule number $(r=1,2, \ldots, R)$;

$A_{i r}=1,2, \ldots n$ are fuzzy sets representing linguistic descriptions of the of the patterns features (sometimes, often, always) and

$\mathrm{C}_{\mathrm{jr}}=$ defines the name of the output class, where $j \mathrm{E}(1,2)$, represents the occurrence of an EE or NEE, respectively.

The $\mathrm{C}_{3}$ layer represents the exit units, one for each class (EE or NEE). The weights of the connections $C_{2}$ e $C_{3}$ layers are fixed in 1. Each unit in $C_{3}$ layer calculates its entry value as the sum of the exit weights of these units in layer $C_{2}$.

The second implemented model is related to the utilization of Einstein's Sum/Product fuzzy arithmetic operations ${ }^{3}$, as shown in Fig 1.

Layer 1: each node of this layer represents linguistic features of the input patterns. It is the layer which receives the data from the external environment and converts the patterns into fuzzy categories. The layer 1 presents fourteen input patterns.

Layer 2: the function in the layer 2 nodo is to perform antecedent matching of the inputs against the fuzzy sets they represent and compute a similarity measure known as the membership value (MV).

Layer 3: each node in this layer represents the IF part of the network fuzzy rule-base using the Einstein's Product fuzzy arithmetical operation. Each rule computes the degree of current inputs fulfillment of the with respect to the antecedents of the fuzzy rule;

Layer 4: each node in this layer represents the THEN part of the rules using the Einstein's Sum fuzzy arithmetical operation that hold the consequent of the fuzzy rules in layer 3;

Layer 5: this layer represents the output of the NFS, representing an EE or NEE.

The network is trained following from: (1) an training and test base; (2) an initial rules base with one hundred and forty-nine fuzzy rules which were implemented jointly with the medical expert who accompanies the research development. 


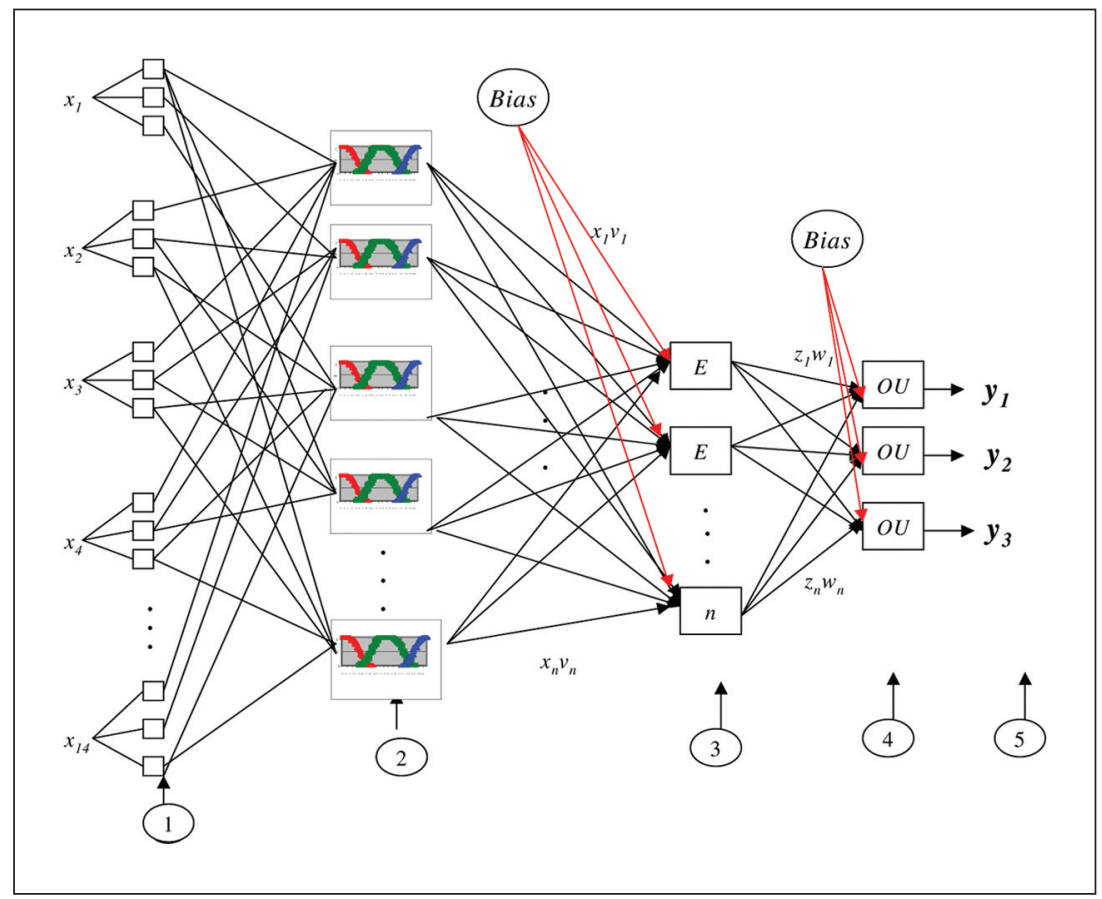

Fig 1. Artificial neural network with backpropagation learning algorithm.

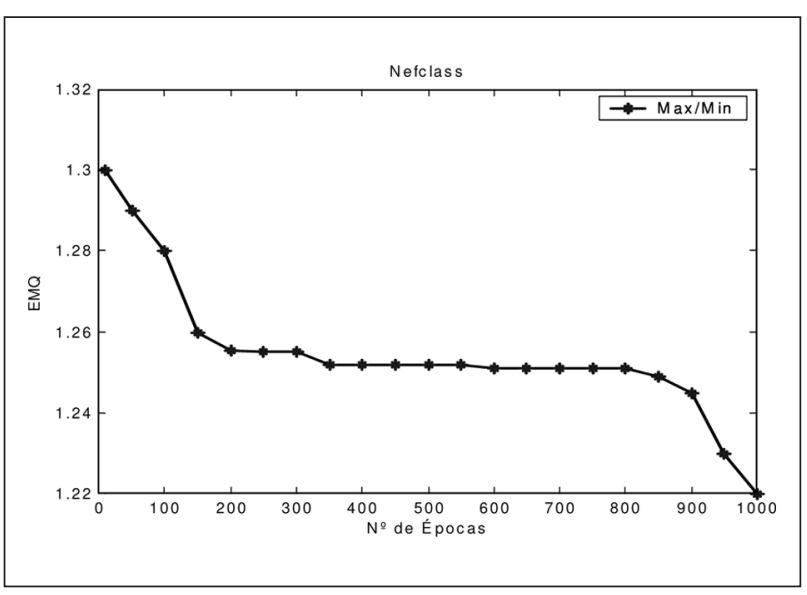

Fig 2. Max/Min fuzzy pattern arithmetic operations.

\section{RESULTS}

After implementing the different fuzzy arithmetic operations, SME results by epoch, variation of the SME absolute rate and hit percentage in the training phase are described.

In the $\mathrm{max} / \mathrm{min}$ fuzzy pattern arithmetic operations implemented with the NEFCLASS, SME remained between the values [1.30; 1.22], presenting a SME average of 1.22 and an SME absolute rate variation of 0.002 (Fig. 2). The number of right decisions at the training and test phase, presented by the NEFCLASS, was $83,60 \%$. It was noticed that SME decreased to the epoch of 200; afterwards, the learning remained stable, and only from the 850 epochs that learning returned to present better results.

SME referring to Einstein's Product/Sum fuzzy arith-

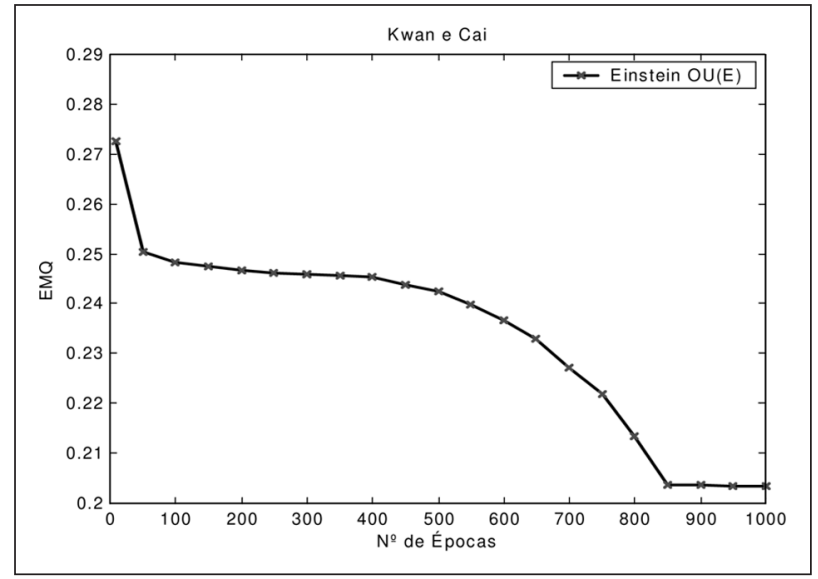

Fig 3. Einstein's Product/Sum fuzzy arithmetical operations.

metical operations remained between the $[0.27 ; 0.20]$ values, with a SME average of 0.21 and a SME absolute rate variation of 0.001 (Fig 3). The number of right decisions at the training and test phase, presented by the ANNB, was $90,16 \%$. It was noticed that SME minimized gradually close to the 850 epochs, and afterwards, learning remained stable until the end of training.

\section{DISCUSSION}

Only the results related to NEFCLASS architecture were confronted with literature, because up to now it has not been found references to the consulted literature related to the exploration of the different fuzzy arithmetic operations which are proposed for the research. The found 
results, using the $\mathrm{max} / \mathrm{min}$ fuzzy pattern arithmetic operations with NEFCLASS, prove their similarity, by showing percentage hits which are compatible with the consulted literature. Conde, Ramos and Vasconcelos investigated two neuro-fuzzy systems: (1) breast cancer and (2) diabetes mellitus which presented a hit percentage of $98.28 \%$ and $76.72 \%$, respectively ${ }^{25}$. Serhatlioglu et al. investigated diabetes mellitus in (left and right) ophthalmic arteries and in the carotid arteries, obtaining a hit percentage of $85.0 \%, 87.5 \%$ and e $85.0 \%$, respectively ${ }^{26,27}$. Nauck and Kruse explored a neuro-fuzzy system in order to diagnose breast cancer by presenting a hit percentage of $96.5 \%{ }^{24}$.

For the sensibility and specificity percentiles related to NFS in order to diagnose visual glaucoma, it found hit percentiles of $96.0 \%$ and $93.4 \%{ }^{28}$.

The architecture explored in this research showed smaller results: $84.90 \%$ and $82,60 \%$, respectively.

In conclusion, from the implementations which were done NEFCLASS and the ANNB, one has noticed that the $\mathrm{max} / \mathrm{min}$ fuzzy pattern arithmetic operations and the Einstein's Product fuzzy arithmetic operation stayed at stable rates of hit, both in either the training phase and the network test phase. The ANNB presented a smaller SME than NEFCLASS model in the test phase.

From the results presented in the internal validation of the knowledge base, the best sensibility result was attained by means of $\mathrm{max} / \mathrm{min}$ fuzzy pattern arithmetic operations $(84,90 \%)$. The best specificity result was attained by using the fuzzy neuron proposed by Kwan-Cai by means of Einstein's Product/Sum fuzzy arithmetic operations (95.65\%). The best percentiles of positive predictable value was attained by means of Kwan-Cai's fuzzy neuron by using the Einstein's Product/Sum fuzzy arithmetic operations (93.61\%). As negative predictable value, the NEFCLASS architecture, along with Kwan-Cai's fuzzy neuron presented similar results ( $87.69 \%$ and $88.00 \%$ ), respectively.

After applying the hypothesis test to proportions, it was verified that NEFCLASS is similar to ANNB architecture, presenting a value "p" of 0.3438 and 0.4705 respectively in relation to specificity and positiveness predictable value, an ANNB architecture was better than the NEFCLASS architecture, showing a value " $p$ " of 0.00053 and 0.00043 , respectively.

The development of an NFS based on the utilization of these fuzzy arithmetic operations is justified, given the importance that involves the handling of different operations in the fuzzy rules base, leading to a bigger or smaller system hits rate. This technique could be used widely in a variety of medical areas.

\section{REFERENCES}

1. Mandani EH. Application of fuzzy algorithm for control of simple dynamic plant. In: Proceedings of IEEE Control and Science 1974;121:15851588.

2. Nauck D. A fuzzy perceptron as a generic modelfor neuro-fuzzy approaches. In: Proc. Fuzzy-systeme - 2nd GI-Workshop, Siemens Corporation, Munich: 1994:91-99.

3. Klir G, Yuan B. Fuzzy sets and fuzzy logic: theory and applications. USA: Prentice, 1995.

4. Kwan HK, Cai T. A fuzzy neural network and its application to pattern recognition, IEEE transactions on fuzzy systems 1994;3:185-193.

5. Fernandes JG. Epidemiologia das crises epilépticas em Porto Alegre: um estudo populacional. Tese. Porto Alegre: UFRGS, 1993.

6. Comission On Classification and Terminology of the International League Against Epilepsy. Proposal for revised clinical and electroencephalographic classification of epileptic seizures, Epilepsia 1981;22: 489-501.

7. Nassar SM. Estatística e informática: um processo interativo entre duas ciências. Florianópolis: Ed. da Universidade Federal de Santa Catarina, 1998.

8. Devore JL. Probabilidade e estatística para engenharias e ciências. São Paulo: Ed. Thomson Pioneira, 2006.

9. Word Helth Organization (WHO). The World Health Report 2001. Mental health: New Understanding, New Hope. Geneva, WHO, 2001.

10. Kaplan I. Sandock BJ. Compêndio de psiquiatria. Artes Médicas, Porto Alegre, 1997.

11. Oliveira J, Gouveia OO. Transtornos psiquiátricos associados à epilepsia. Rev Psiquiatr Clín 2003;30:160-164.

12. Guerreiro CAM, Guerreiro MM, Cendes F, Cendes IL. Epilepsia. São Paulo: Lemos Editorial, 2000.

13. Costa JC da, Palmini A, Yacubian ELMT, Cavalheiro EA. Fundamentos neurobiológicos das epilepsias: aspectos clínicos e cirúrgicos. São Paulo: Lemos Editorial, 1988.

14. Fernandes JG, Schmidt MI, Monte TL, et al. Prevalence of epilepsy: the Porto Alegre study. Epilepsia 1992;33:128-132.

15. Denoeux T, Masson MH. Principal component analysis of fuzzy data using autoassociative neural networkworks, IEEE Transactions on Fuzzy Systems 2004;12:336-349.

16. Vellasco MMBR, Pacheco MAC, Networko LSR, Souza FJ. Electric load forecasting: evaluating the novel hierarchical neuro-fuzzy BSP model. Int J Electrical Power Energy Systems 2004;26:131-142.

17. Fortuna L, Rizzo L, Sinatra M, Xibilia MG. Control Engineering Practice 2003;11:1491-1500.

18. Aguiar L, Melin P, Castillo OO. Intelligent control of a stepping motor drive using a hybrid neuro-fuzzy ANFIS approach. Applied Soft Computing 2003;3:209-219.

19. Azevedo FM, Brasil LM, Oliveira CL. Redes neurais com aplicações em controle e em sistemas especialistas. Florianópolis: Bookstore 2000.

20. Buckley JJ. An Introduction to fuzzy logic and fuzzy sets, advances in soft computing. USA: Physica-Verlag, 2002.

21. Fullér R. Introduction to neuro-fuzzy systems. USA: Physica-Verlag, 2000.

22. Gorzalczany MB. Computational intelligence systems and applications. USA: Physica-Verlag, 2002.

23. Rezende SO, Evsukokk AG, Garcia ACB, et al. Sistemas inteligentes: fundamentos e aplicações. São Paulo: Editora Manole, 2003.

24. Nauck D, Kruse R. A neuro-fuzzy method to learn fuzzy classification rules from data. Fuzzy Sets and Systems 1997;89:277-288.

25. Conde GA, Ramos PG, Vasconcelos GC. Neuro-fuzzy networks for pattern classification and rule extraction. In: Simpósio Brasileiro de Redes Neurais, 2000. Disponível em <http:/ / csdl.computer.org/ comp/ proceedings/sbrn/>. Acesso em 25 Set, 2006.

26. Serhatlioglu S, Bozgeyik Z, Ozkan Y, Hardalac F, Güler I. Neuro-fuzzy classification of the effect of diabetes mellitus on carotid artery. J Med Systems 2003;27:457-464.

27. Serhatlioglu S, Hardalaç F, Kiris A, Ozdemir H, Yilmaz T, Güler I. A neuro-fuzzy classification system for the effects of diabetes mellitus on ophthalmic artery. J Med Systems 2004;28:167-176

28. Garcia-Feijoo J, Carmona EJS, Gallardo LM, et al. Development of an automatic discrimination system for glaucomatous visual fields based on neuro-fuzzy nets. Arch Soc Esp Oftalmol 2002;77:669-676. 